\section{A fan writes}

\section{NASA/TREK: Popular Science and} Sex in America

by Constance Penley

Verso: 1997. Pp. 169. \$64.95, £35 (hbk); \$14, $\mathfrak{E} 11$ (pbk)

\section{Oliver Morton}

Just before writing this review I was looking for a US Air Force document on the World Wide Web. It turned out to be on a server called Tuvok - the name of the Vulcan security officer on the eponymous Starship Voyager in the fourth of the Star Trek television shows. From seeing this name, I learnt a little about the self-image and style of this corner of the military industrial complex. I also recognized again the force of Constance Penley's case in NASA/TREK: that Star Trek is everywhere, and that the way people make use of it can reveal a lot about science, technology and - her particular interest - sex.

As Penley argues, "going into space" is the governing metaphor by which people understand the world of science and technology, not to mention their place in that world as women and men. And Star Trek is the dominant vision of space travel in today's culture.

Penley looks at the way this body of modern myth has been appropriated by two very different groups, one mostly of white male engineers, many of them in America's South, the other of heterosexual women with "pinkcollar, 'subprofessional' and high-tech service industry" jobs, many in California. The first group - the National Aeronautics and Space Administration (NASA) - has attempted to lay claim to the television pro-

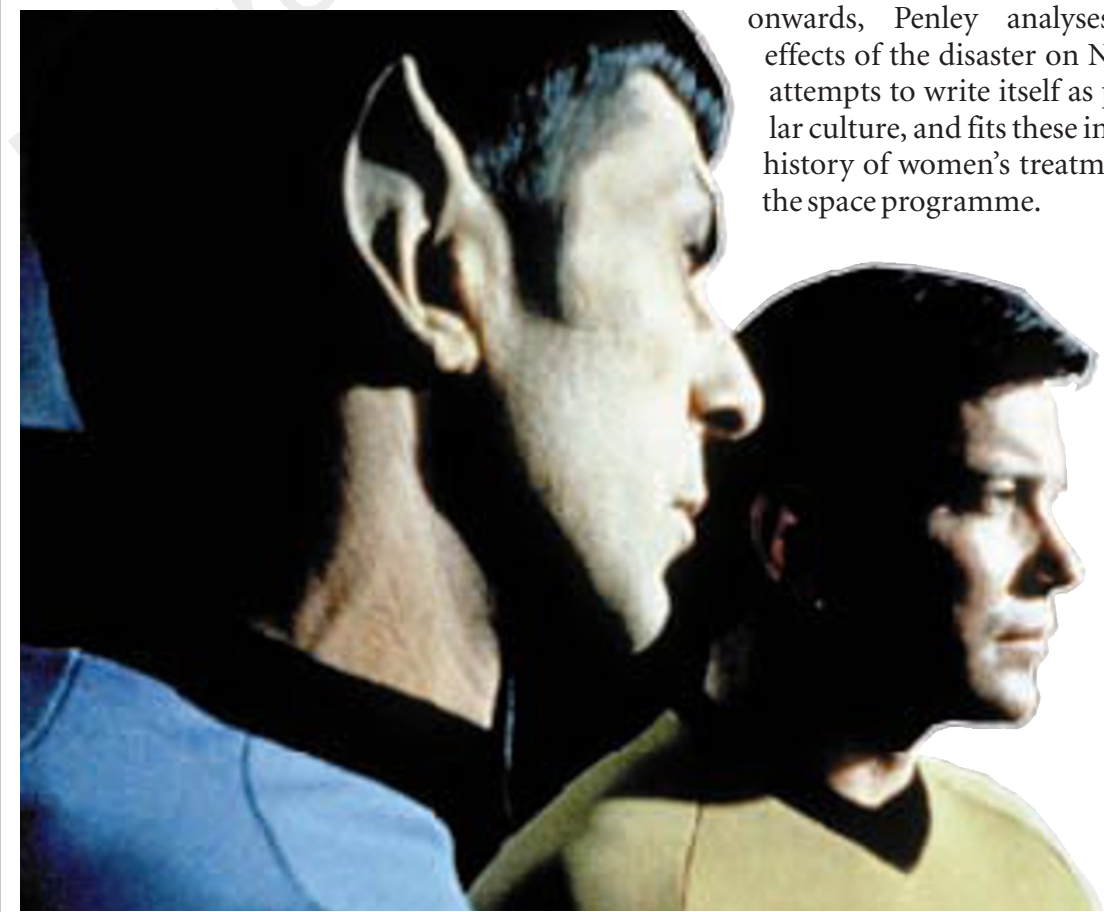

"Those pink-collar women think we're lovers. Surely that's illogical, Captain ..."

gramme's Utopian vision of spaceflight. The second group - the "slashers" - has entertained itself producing and distributing pornographic romances centred on a physical relationship between Captain Kirk and Mr Spock. This is the world of "K/S" fiction: the slashers take their name from the punctuation between their subjects' initials.

Unsurprisingly, NASA and the rest of the US aerospace establishment are more than willing to link themselves to Star Trek, both out of genuine affection and as good public relations. There has been a Star Trek exhibition at the Smithsonian National Air and Space Museum; the first (non-orbital) space shuttle was called the Enterprise; the planned replacement for the Hubble is known as Space Telescope Next Generation; the first black female astronaut prefaced her transmissions with Lieutenant Uhura's catchphrase "Hailing frequencies open".

Penley sees NASA as attempting to define its place in popular culture as the practical realization of Star Trek's Utopian 'theory' of space travel. She herself sees the relationship between the two 'narratives' as a little deeper than that; like the slash in K/S, the slash in NASA/TREK stands for a more intimate and subversive reading of a relationship normally taken at face value.

Most of the first half of Penley's book is devoted to the Challenger disaster and the death of schoolteacher Christa McAuliffe, with whose carefully chosen mediocrity television-watching America was supposed to identify. (Pam Dawber, star of the alienaround-the-house sitcom Mork and Mindy, was presumably given her place on the selection panel to spot someone with the requisite girl-next-doorness.) From tasteless jokes onwards, Penley analyses the effects of the disaster on NASA's history of women's treatment in . as popu-

In the second part of the book, she turns her attention to the slashers and finds that they have rewritten the Trek myth to their own ends far more successfully. By choosing to "work with what's out there", the slashers have created a literature about sex and Utopia that does not repress the body or subjugate women and that cuts across race (indeed species) barriers. The women who create these fictions go from being passive viewers to active creators: they confess themselves much more embarrassed to be known as television fans than as pornographers.

As is often the way with cultural studies, NASA/TREK succeeds not so much by force of argument as by the accumulation of telling details and resemblances. Penley provides plenty of them and teases out their relationships provocatively. Although there are places where one would like a little more reporting - how did the quasi-military world of NASA/TREK respond to the gays in the military debate? - the book succeeds most admirably in its own terms.

It also does more. It reveals a way of talking about science that is widely ignored and utterly undervalued: that of the fan. People who are not fans find it hard to understand the nature of the fan's relationship to his or her field, be it Arsenal football club, the Grateful Dead, Star Trek or whatever. The fans are experts, they are enthusiasts, they are critics and they are creators, writing stories, publishing 'zines and remixing bootleg tapes. They know the details and they delight in spotting the mistakes, but at the same time they imbue with value and significance whatever it is they're attached to. They are a community of consumption convinced it is central to the whole process of production.

The sciences have boosters, enthusiasts, amateur practitioners and - I fear - even worshippers. But only rarely do they have the sort of organized fandom common to sports and genre fiction. There are exceptions: it is not to belittle them to say that some AIDS activists share the attributes of fans, attacking science when it fails them but valuing it highly at the same time. But, in general, the idea of a community of nonpractitioner enthusiasts, fiercely critical when the rules are broken and convinced that they are central to the process, is alien to most of science, and that is a great pity.

The fan's dual nature as insider and outsider provides a voice that could be valuable in areas where the social implications of science matter, a voice that can promote debate without entrenching hostility. Much of the power of Penley's book is that she writes as a fan of both NASA and Star Trek, with a vivid appreciation of what fun fans can have and what good they can do. More such fans are urgently needed elsewhere.

Oliver Morton, formerly editor of UK Wired and science editor at The Economist, is at The Apse, 142 Greenwich High Road, London SE10 8NN, UK. 